\title{
LOS ESTUDIOS DE CULTURA POLÍTICA EN ESPAÑA
}

\section{María Luz Morán}

Universidad Complutense

E-mail: memoran@redestb.es

\begin{abstract}
RESUMEN
Los estudios de cultura política han tenido un papel muy destacado en la investigación sociopolítica española. El decenio comprendido entre mediados de los sesenta y la muerte de Franco marca la recepción del paradigma clásico de la cultura política y los primeros pasos de su aplicación en los estudios del proceso de modernización, en los análisis de la evolución del régimen franquista y en los atisbos iniciales del inevitable cambio político. Por su parte, las interpretaciones más difundidas sobre la naturaleza de la transición política hicieron hincapié en la existencia de unos prerrequisitos culturales que facilitaron la democratización. Ello hizo posible que las élites llegaran a establecer un pacto básico sobre el que se construyó, en un lapso de tiempo muy breve, una democracia comparable a la de los países de la Europa occidental. A lo largo de los años ochenta y noventa se ha mantenido el interés por el estudio de la cultura política de los españoles. Sin embargo, la rutinización de la vida democrática ha dado lugar a un cierto cambio de énfasis en la agenda de los temas de investigación.
\end{abstract}

\section{EL DEBATE EN TORNO AL CONCEPTO DE CULTURA POLÍTICA}

Quizá no sea una exageración afirmar que la cultura política ocupa un lugar destacado entre el conjunto de conceptos acuñados por las ciencias sociales que, si bien nunca han llegado a satisfacer plenamente a ninguno de los autores que lo han empleado como herramienta de análisis, han tenido la «fortuna» de ser asimilados plenamente en los discursos políticos de las élites, en

\section{Reis}


las jergas que transmiten los medios de comunicación y, en suma, en nuestros vocabularios cotidianos. En sí mismo, este hecho no es negativo; bien al contrario, podría entenderse como un signo alentador de la penetración de nuestras disciplinas en esferas cada vez más amplias de la vida social, si no fuera porque la cultura política ha sido, desde el mismo momento en que comenzó a difundirse en la reflexión social y política, un término inevitablemente incómodo. Tanto es así que prácticamente todos aquellos que lo utilizan parecen sentir una imperiosa necesidad de justificar, una y otra vez, de forma prolija, y en muchas ocasiones excesiva, las ambigüedades inherentes al propio concepto, las limitaciones de su alcance y, en suma, los riesgos de seguir operando con un instrumento de análisis tan elástico y escurridizo que siempre parece estar a punto de escapársenos de entre las manos. Hace ya algunos años recurrí a la tragedia de Sísifo para tratar de dar cuenta de esta mezcla de tedio, cansancio y fatalidad que embarga a quien se enfrenta a la tarea de describir la situación de los estudios de cultura política, acotando su campo de análisis y estableciendo sus principales logros y sus más evidentes limitaciones.

Sin duda, las controversias epistemológicas y metodológicas que ha suscitado dicho concepto, al menos a lo largo de los últimos cuarenta años, tienen mucho que ver con su relevancia en el análisis sociopolítico y con el hecho de que el propio término afecta de lleno a uno de los grandes interrogantes que alentaron desde sus orígenes la especulación en torno a las bases sociales de los fenómenos políticos. La cultura política, bajo cualquiera de las diversas denominaciones que ha recibido, remite a los complejos vínculos que se tejen entre la esfera pública, la vida política y los universos o representaciones que sobre ésta poseen los miembros de toda comunidad política. Tratar de aprehender el modo en que se interrelacionan y se afectan mutuamente los valores, creencias, actitudes, lenguajes y discursos de las personas y grupos sociales en relación a lo público con los principales elementos constitutivos de los sistemas políticos y de la vida pública se convierte, así, en el campo de referencia de la reflexión en torno a la cultura política. Establecer los puentes entre los marcos culturales, psicológicos y sociales de la acción y las realidades concretas de los sistemas políticos aparece como una exigencia de las nuevas miradas que desde las ciencias políticas y sociales se dirigen hacia los intrincados procesos de cambio de las sociedades contemporáneas. El esfuerzo está guiado por una intuición común: la esterilidad de construir marcos de explicación relevantes y convincentes de dichos procesos sin dar cuenta de esa dimensión «oculta» que convenimos en denominar cultura política.

Los escollos y desacuerdos a la hora de establecer su "campo semántico» y la forma de operacionalizarlo en la investigación aplicada derivan de la propia envergadura del proyecto y del proceso histórico de institucionalización de las ciencias sociales, que, a lo largo de nuestro siglo, se ha escorado siempre más hacia la fragmentación y a la defensa de parcelas de poder académico o profesional que a la comunicación y al trabajo en común. Una buena parte de las dificultades que arrastra la cultura política proviene, a mi juicio, de la fuerte 
resistencia a admitir que se trata de un concepto fronterizo, ubicado en la intersección de, al menos, cinco disciplinas: la sociología, la ciencia política, la antropología, la psicología y la historia. Sólo un esfuerzo común por hacer converger las miradas desde perspectivas distintas y por aplicar conceptos, métodos e instrumentos de análisis de distintos "propietarios» contribuirá a hacernos salir de este círculo vicioso y a superar una visión restrictiva que J. Alexander (1982) ha denominado el empleo de la cultura política como "categoría residual».

Durante algunas décadas, la sociología y la ciencia políticas, quizá atenazadas por su propia inseguridad de «jóvenes» disciplinas y ocupadas en estériles discusiones acerca de los límites de su competencia, dieron la espalda a una realidad que se ha ido imponiendo cada vez con más fuerza en los últimos tiempos. No sólo son estos terrenos fronterizos los más fértiles para el avance de nuestro conocimiento sobre las sociedades contemporáneas, sino que, además, las ciencias sociales están embarcadas en un movimiento imparable hacia la eliminación de las viejas fronteras cuya estrechez de miras se ha visto superada por la propia lógica de desarrollo del conocimiento social y por la naturaleza de los principales cambios sociales y políticos acaecidos en las últimas décadas (Wallerstein, 1995).

Irónicamente, el objetivo de este artículo me exige volver a asumir una tarea que apunta en dirección contraria a este proceso de apertura que acabo de defender. Obliga, una vez más, a empuñar los utensilios del agrimensor para operar como si fuera posible establecer con precisión los lindes del campo de estudio, establecer sus medidas y sus principales características topográficas, señalar aquellas parcelas mejor cultivadas dando cuenta del tipo de frutos que se recolectan y, finalmente, decidir cuáles son los campos en los que se hace necesaria una labor de mejora. Esforzarse por levantar mapas de terrenos que nos preciamos de conocer bien es, en todo caso, un ejercicio intelectual altamente recomendable. Nos empuja a reconocer, una vez más, el territorio, observando sus principales características, sin perder de vista en momento alguno que el objetivo final de nuestro trabajo es producir un documento que permita orientarse a quienes no están familiarizados con dicho espacio. Ello supone determinar cuál es la información más relevante que deseamos seleccionar pero, también, representarla y narrarla de forma clara y concisa. Quizá la labor del hacedor de mapas sea, simplemente, el esfuerzo siempre fallido por lograr una solución tan simple, y al tiempo tan precisa, como la que se le ocurrió a la ingeniosa Ariadna cuando le entregó a Teseo, a las puertas del laberinto, un ovillo de lana.

Así pues, a partir de este momento proseguiré como si mis instrumentos de medición fueran rigurosos y mi territorio poseyera contornos bien dibujados. Pero el lector hará bien en recordar que desde los orígenes del pensamiento social las disputas por su control han sido numerosas y sus fronteras siempre fluctuantes y, sobre todo, no deberá olvidar que algunas de las contribuciones más significativas al estudio de la cultura política se han producido en espacios 
supuestamente ubicados más allá de sus límites. Desde que ya en el siglo XVIII autores como Montesquieu comenzaron a dar cuenta del influjo de la cultura de los pueblos en su forma de organización política, bajo uno u otro nombre y con distintas argumentaciones, la cultura política se convirtió en un tema clásico en el análisis político que ha estado siempre asociado a algunas de sus preocupaciones tradicionales; en concreto, es inseparable de la reflexión acerca de la legitimidad de los sistemas políticos y de la larga discusión en torno al surgimiento y a la función que en la modernidad cumple la opinión pública. Sólo tiempo después, ya bien avanzado el siglo XX, la cultura política adquirió la estrecha vinculación con el que se convertiría en el leit-motiv, por no decir en la obsesión, de algunas corrientes hegemónicas dentro del análisis político: hallar los fundamentos de la estabilidad de los sistemas políticos y, más concretamente, de los democráticos.

Como ya se ha repetido en tantas ocasiones, al final de la segunda guerra mundial el clima intelectual y las exigencias de la reconstrucción económica y política de una buena parte de la Europa occidental marcaron la institucionalización de las modernas disciplinas de la sociología y ciencia políticas. La exigencia de estudiar las «democracias realmente existentes» determinó, junto con el desarrollo de los estudios de comportamiento político y los más claramente institucionales, volver a situar en primer plano la cuestión de las bases culturales de los sistemas políticos. En este contexto aparece la contribución de La cultura cívica, de G. Almond y S. Verba (1970), y es también este mismo clima intelectual el que contribuyó a convertirla en una investigación precursora, una gran línea de trabajo que, durante ya casi cuarenta años, ha marcado de forma determinante la línea que han seguido las investigaciones aplicadas de cultura política y una buena parte de la reflexión teórica.

Tal y como afirma J. Botella (1997), las propuestas de Almond y Verba encerraban promesas enormemente atractivas para los estudios de la época. En primer lugar, ofrecían un factor de estabilidad en medio de un mundo que había sido sometido a fracturas y transformaciones que pocos podían haber imaginado pocos años antes del estallido de la guerra. La cultura política implicaba durabilidad en la medida en que se asumía la premisa de la lentitud del cambio cultural frente al de las esferas económica, política o social. En segundo lugar, dicha versión de la cultura política se mostraba fácilmente operacionalizable y confiaba casi exclusivamente en las encuestas de opinión como técnica de investigación capaz de traducir las opiniones de los individuos en un material susceptible de un tratamiento estadístico cada vez más sofisticado. Y, por último, esta propia fe en la operacionalización de la cultura política permitía atender a una de las máximas exigencias de los estudios sociopolíticos de la época: la comparación entre casos distintos con el fin de contribuir a un conocimiento riguroso de las bases de la estabilidad de los sistemas democráticos. Quizá entonces se produjo la cesura, mantenida prácticamente inalterable hasta la actualidad, entre dos modelos distintos de concebir y operar con la cultura política. Un proyecto comparado que, sin duda, ha sido el dominante, 
al menos en lo que se refiere al volumen de investigación que ha generado y a su repercusión en el discurso de las ciencias sociales y políticas; y un proyecto sociológico, mucho menos visible y periférico, al menos hasta la década de los ochenta, que no apunta a la comparación sino al conocimiento más profundo del modo en que se vertebran culturas, modos de acción social y esferas de lo público. Para S. Welch (1993), la lógica de ambos proyectos parece, aún hoy en día, irreconciliable; lo que el primero aporta en extensión y generalización de las diferencias y similitudes entre los principales rasgos de las culturas políticas en ámbitos geográficos y temporales distintos lo hace a costa de perder la profundidad y fineza de análisis que el segundo logra renunciando a la comparación.

La supremacía del modelo formulado por Almond y Verba en la investigación sociopolítica en España hace aconsejable recordar, aunque sea de forma esquemática, los principales elementos de su propuesta:

a) Una definición de cultura política bien conocida: «La cultura política de una nación consiste en la particular distribución de las pautas de orientación hacia objetivos políticos entre los miembros de esta nación» (Almond y Verba, 1970, p. 31).

b) Una clasificación de los tipos de orientación política que forman la cultura política inspirada en la obra de T. Parsons y E. Shills: orientaciones cognitivas, afectivas y evaluativas. Los objetos políticos hacia los que se dirigen las orientaciones de los individuos son básicamente cuatro: el sistema político como objeto general, los objetos políticos (input), los objetos administrativos (output) y el propio sujeto considerado como objeto político.

c) Las características de la cultura cívica (aquella que corresponde a los sistemas democráticos estables) se establecen como resultado de un estudio histórico del proceso de desarrollo político británico. Por consiguiente, es entendida como una cultura pluralista, basada en la comunicación y en la persuasión, en el consenso y en la diversidad; una cultura que permite el cambio pero que, sobre todo, lo modera. La cultura cívica es, pues, el resultado de los choques entre la modernización y el tradicionalismo.

d) A partir de la cultura cívica se hace posible construir la conocida clasificación de los tres tipos ideales de cultura política: la parroquial, la de súbdito y la participante. Toda cultura política «real» se entiende como una cultura híbrida que presenta siempre elementos de los tres tipos en proporciones dispares.

e) Aunque Almond y Verba reconocen explícitamente la necesidad de dar cuenta de la existencia de «subculturas políticas» de los distintos grupos sociales que componen su unidad de análisis por excelencia, el Estado-nación, existe en su obra una mayor insistencia en la homogeneidad de la cultura política que en su diversidad e incluso enfrentamiento.

f) La relevancia de la cultura política radica en que, como instrumento de análisis, permite plantear la conexión entre las tendencias psicológicas de 
los sujetos y grupos, entre la estructura y el proceso político, entre la micro y la macropolítica: "... la relación entre la cultura política y la estructura politica se transforma en uno de los aspectos significativos más investigables del problema de la estabilidad y la evolución políticas» (Almond y Verba, 1970, p. 51).

La oleada de críticas que suscitaron las tesis de La cultura cívica es bien conocida y ha jalonado las controversias sobre la cultura política a lo largo de ya casi cuatro décadas. Una buena parte atañe a la asunción acrítica del análisis sistémico parsoniano traducida en una concepción simplista de la cultura que ha impedido durante largo tiempo entablar un diálogo fructífero con el debate en torno al concepto que, paralelamente, ha ocupado un lugar destacado en el desarrollo de disciplinas afines como la antropología. Desde la sociología y la ciencia política se ha resaltado el sesgo conservador de una concepción eurocentrista de los procesos de modernización que toma como referente único el modelo idealizado de la democracia anglosajona, relegando a un segundo puesto el conflicto, las desigualdades y las líneas de fractura en los procesos históricos de democratización y su impacto en la paralela constitución de las culturas políticas ${ }^{1}$. Por último, íntimamente vinculada con la puesta en cuestión de las bases filosófico-ideológicas del trabajo de Almond y Verba se ha desarrollado una crítica centrada en las limitaciones de la aplicación de las técnicas cuantitativas de investigación social, en concreto las encuestas de opinión, como métodos de análisis capaces de aprehender los procesos a través de los cuales surgen, se aprenden, mutan, permanecen y se emplean las culturas entendidas como instrumentos mediante los cuales las personas y grupos atribuyen significados a los mundos que los rodean. Procesos que, en consecuencia, se convierten en elementos decisivos para comprender tanto sus comportamientos como la naturaleza y funcionamiento de las principales instituciones políticas y sociales.

En todo caso, los estudios de cultura política fueron adquiriendo a lo largo de las décadas de los sesenta y setenta un sólido estatuto tanto en el mundo académico como en la práctica investigadora. A pesar de que el paradigma tradicional fue seriamente atacado desde una sociología crítica cada vez más poderosa, desde posiciones próximas a la hermenéutica interesadas por una nueva reflexión en torno a la cultura y desde las formulaciones renovadas del argumento utilitarista que postulaban los defensores de las teorías de la elección racional ${ }^{2}$, éste fue no sólo capaz de sobrevivir, sino de seguir produciendo un volumen realmente notable de investigación aplicada ${ }^{3}$. No obstante, cabe reconocer que fue prestando cada vez mayor atención a los debates y contribu-

${ }^{1}$ El texto de Pateman (1980) sigue siendo una referencia ineludible para conocer los principales argumentos de esta crítica. Puede también consultarse a Bachrach (1967).

2 Se pueden encontrar análisis detallados de los debates en torno a la cultura política desde estas posiciones dispares tanto en el libro de Welch (1993) como en el de Gibbins (1989).

3 Para una exposición más detallada sobre dicha investigación puede consultarse Botella (1997), Llera (1997), Morán y Benedicto (1995) y Morán (1996). 
ciones que producían sus críticos y que fueron adquiriendo progresivamente una mayor visibilidad hasta producir, en los años ochenta, lo que algunos autores han denominado un «retorno de la cultura a un primer plano» ${ }^{4}$.

El desarrollo de las ciencias sociales en España en los años que marcaron el surgimiento y consolidación de la cultura política como campo de estudio fue particularmente dificultoso. El franquismo frenó casi en seco la evolución del rico debate generado en nuestro país desde finales del siglo pasado y que se había traducido en los primeros pasos de la institucionalización de la sociología y la ciencia políticas. Pero, además, hay que recordar los adicionales obstáculos que tuvieron que superarse para contrarrestar el domino de la tradición jurídica como perspectiva hegemónica de análisis. En este contexto, la reflexión sobre la cultura política en España presenta dos rasgos aparentemente contradictorios. Por un lado, el debate de fondo ha tenido un escaso eco en la comunidad académica, siendo prácticamente nulas las contribuciones españolas a la discusión teórica y metodológica. Nuestra literatura se limita a una tarea de recolección y divulgación de las principales polémicas, sin que haya existido una especial preocupación por reflexionar sobre la raíz del problema. Pero, paralelamente, el modelo hegemónico de aplicación de la cultura política ha tenido un papel muy destacado en la investigación sociopolítica desde los años setenta hasta la actualidad. Me dispongo ahora a analizar el marco en el que se ha producido este florecimiento, las características principales de los estudios publicados y algunas de las conclusiones más difundidas acerca de la cultura política de los españoles.

\section{LA RECEPCIÓN DE LOS ESTUDIOS DE CULTURA POLÍTICA EN ESPAÑA}

La recepción de los estudios de cultura política en España tuvo lugar en la segunda mitad de los años sesenta, siendo adoptada como herramienta de análisis por aquella generación de científicos sociales que, por primera vez desde el fin de la guerra civil, cursaron sus estudios de postgrado en el extranjero y cambiaron el destino tradicional de los intelectuales españoles de la primera mitad de siglo (Francia o Alemania) por la que ya entonces era la gran potencia intelectual del mundo occidental: los Estados Unidos. La influencia de la escuela funcionalista y de su modelo del tránsito de la sociedad tradicional a la moderna es la principal vía por medio de la cual la cultura política aparece íntimamente asociada a dos grandes líneas de trabajo que, en la época, centraban el interés del análisis sociopolítico.

En primer lugar, dicho impacto es especialmente notable en el auge que

${ }^{4}$ Un ejemplo notable de una aplicación de la cultura política a un análisis con claras conexiones con las teorías de la elección racional es el de Putnam (1993). Su concepto de "capital cultural» se cuenta entre los más influyentes en el análisis sociopolítico de los últimos años. 
adquirieron los estudios sobre la modernización en España que tomaron como referencia la gran teoría funcionalista de los años cincuenta-sesenta. Los cambios producidos por el boom económico de los sesenta se convirtieron en un tema inevitable de análisis. Evidentemente, el objeto principal de esta corriente fueron los grandes procesos de transformación de la estructura social, entre los que se destacaron la urbanización, la emigración, las transformaciones demográficas y la industrialización. Sin embargo, de una manera inevitable, la reflexión sobre el impacto de estas transformaciones en la sociedad española llevó a considerar el paralelo cambio de los sistemas de valores predominantes en los distintos grupos sociales que la componían. De este modo, temas como la secularización, el cambio en las relaciones familiares o el inicio del rápido proceso de transformación de los roles atribuidos a las mujeres fueron convirtiéndose en objetos destacados de reflexión. Por ello, sin abordar de una forma directa el estudio de las actitudes y valores con respecto al sistema político, el argumento básico de la cultura política comenzó a estar presente implícitamente en dichos estudios. Sólo en los años inmediatamente anteriores a la muerte de Franco, cuando el problema de la continuidad o ruptura del régimen pasó a ocupar un primer plano, el tema se abordó directamente.

El paso del estudio de los valores al de la cultura política fue una senda natural que se encontró perfectamente legitimada no sólo por las prioridades que imponían a la reflexión sociopolítica las particulares circunstancias de la coyuntura histórica española, sino fundamentalmente por el apoyo que le brindaban algunos de los elementos centrales de la gran teoría de la modernización. En este sentido, cabe recordar que el argumento implícito que la recorre es una concepción del desarrollo político entendido como adaptación a un proceso previo de modernización que afecta sustancialmente a los valores y estilos de vida de la población. Aunque las investigaciones sobre el impacto de la modernización no se suelen incluir dentro de las historias más convencionales de los estudios de cultura política, éstas constituyen, a mi entender, un primer eslabón imprescindible para llegar a comprender cómo y por qué la cultura política se erigió, unos años más tarde, en un elemento clave en la comprensión del cambio político en España ${ }^{5}$.

Sin embargo, es dentro del análisis sociopolítico concebido en términos más restringidos en donde, al comienzo de los años setenta, apareció la primera formulación explícita de la cultura política. Y es, concretamente, la obra de J. Linz el referente fundamental que se convertiría pocos años más tarde en el modelo a seguir a la hora de reflexionar acerca de las bases culturales del cambio político en España. En su análisis de las crisis políticas y de los procesos de quiebra de las democracias (Linz, 1987), este autor había defendido el papel de

5 En este sentido hay que recordar la importancia de los informes FOESSA $(1970,1975)$ y de los trabajos de Del Campo (1973), Fraga et al. (1973), Rodríguez Osuna (1973) o Pérez Díaz (1979), entre otros, sobre los campos como la juventud, la población o la educación que fueron precursores en el interés implícito sobre los procesos de transformación de los valores. 
una cultura política autoritaria en el derrumbamiento de las democracias en Alemania e Italia. También aplicó las mismas tesis para explicar la quiebra de la Segunda República en España y siguió operando con dicha categoría a la hora de desarrollar su análisis del franquismo y su concepción de los regímenes autoritarios. Linz se convirtió, en este momento, en una figura muy importante para el análisis sociopolítico. En primer lugar, porque en buena medida era un representante destacado de la poderosa escuela pluralista de análisis político y a través de sus enseñanzas y de sus escritos logró introducir en España este marco de análisis y a sus principales autores. En los trabajos de Lipset o Dahl, además, las bases culturales de la construcción de los sistemas políticos y de sus procesos de cambio ocupaban un lugar destacado. Pero Linz fue también uno de los primeros impulsores de la realización de encuestas de opinión de naturaleza sociopolítica en nuestro país, un terreno que experimentaría un enorme desarrollo desde mediados de los setenta ${ }^{6}$.

Ambas líneas de trabajo corrieron paralelas aprovechando el mencionado despegue de los estudios de opinión pública. Este impulso fue favorecido, antes de nada, por el resquicio que permitió la liberalización del régimen a finales de los sesenta y que se tradujo, en lo que aquí nos compete, en una nueva ley de prensa que suavizaba la censura y, sobre todo, en la dinamización del Instituto de la Opinión Pública, creado en 1963 y que luego se convertiría en el actual Centro de Investigaciones Sociológicas. Además de los estudios sobre valores, en este primer período se realizaron ya encuestas que incluían preguntas que evaluaban las opiniones y actitudes de los españoles en relación con el sistema político ${ }^{7}$. La lectura de los textos de los cuestionarios de estos estudios es enormemente instructiva y revela una traslación paulatina del interés de los investigadores. Se percibe cómo sutilmente, pero de forma cada vez más abierta, va tomando forma uno de los principales interrogantes para las ciencias sociales del momento: cerciorarse de la existencia de sólidas bases socioculturales ante un proceso de cambio político cada vez más inevitable habida cuenta de la edad del dictador y de su irreversible deterioro físico.

En este contexto y con las referencias intelectuales a las que antes he aludido, se entiende que se asumiera de forma bastante acrítica, aunque con algunas modificaciones significativas que señalaré más adelante, el modelo clásico difundido por el trabajo de Almond y Verba. La cultura cívica apareció en castellano en 1970 y la obra se difundió rápidamente en los círculos académicos e intelectuales. En todo caso, la recepción directa de este modelo tuvo un conjunto de consecuencias que todavía hoy, casi en el fin del milenio, pesan nota-

La participación de Linz en la elaboración de los informes FOESSA fue determinante para marcar líneas de trabajo en los estudios sociopolíticos y para que el tema de la cultura política ocupara un lugar destacado dentro de éstos. Véase el informe de 1981, coordinado por este autor.

7 Una vez más, es obligado destacar que el Banco de Datos del CIS posee un volumen de encuestas muy notable en el que desde finales de los años sesenta se encuentran preguntas de este tipo. 
blemente en el modo en que la sociología y la ciencia política española abordan su análisis.

Ante todo, se tradujo en una utilización «instrumental» del concepto de cultura política, que evitó entrar en el debate epistemológico y metodológico de fondo que, con mayor o menor fuerza, se había suscitado ya años antes en el mundo académico anglosajón. Fue una decisión que algunos autores califican de sabia, en la medida en que ahorró esfuerzos y debates a las Ciencias Sociales en momentos especialmente críticos para la sociedad española, que demandaba respuestas urgentes ante las incertidumbres y la urgencia de los problemas a los que se enfrentaba. Pero, al mismo tiempo, ha producido una excesiva homogeneidad de los estudios de cultura política en España. Se consideró, además, que era un terreno exclusivo de la ciencia y de la sociología políticas y estas disciplinas tendieron a cerrarse sobre sí mismas, evitando, hasta hace pocos años, entablar cualquier tipo de diálogo con la antropología, la historia o la psicología social. La enorme confianza que depositaba el modelo en la supremacía de las técnicas cuantitativas de análisis, junto con esta carencia de comunicación con otras disciplinas sociales, explica, asimismo, el casi absoluto monopolio de las florecientes encuestas de opinión en las investigaciones de cultura política.

Así pues, el decenio comprendido entre mediados de los años sesenta y la muerte de Franco señala el momento de la recepción del paradigma clásico de la cultura política y los primeros pasos de su aplicación en los estudios sobre el proceso de modernización, en los análisis de la evolución del régimen franquista y en los atisbos iniciales del inevitable cambio político. Pero fue realmente desde 1975, a lo largo aproximadamente de una década, cuando tuvo lugar el gran auge de los estudios de cultura política como uno de los enfoques clave para la comprensión de la transición política española.

\section{LOS MODELOS DE EXPLICACIÓN DEL CAMBIO POLÍTICO EN ESPAÑA Y EL PAPEL DE LA CULTURA POLÍTICA}

En los últimos años setenta y los primeros de la década posterior tuvo lugar la construcción de un modelo de explicación hegemónico del paso del franquismo a una democracia plenamente comparable a las de los países de la Europa occidental. Fue entonces cuando la sociología y la ciencia política españolas contribuyeron de modo decisivo a dar forma a un marco explicativo que tuvo una considerable difusión entre la comunidad académica internacional y que se trató de aplicar, con mayor o menor fortuna, al estudio de otros procesos de cambio político. Dicho modelo, que algunos críticos denominan, no sin ironía, la "transitología» (Edles, 1998), se esforzó por incorporar perspectivas y categorías de análisis provenientes de propuestas teóricas diversas en un intento por construir un marco de interpretación que diera cuenta de la singularidad de un fenómeno histórico que sobrepasaba las explicaciones que propor- 
cionaban las teorías clásicas del desarrollo político. Existen dos líneas principales de análisis que subyacen a esta interpretación dominante de la transición: el modelo funcionalista y el modelo de los actores políticos. En cualquier caso, lo realmente notable es que en ambos la referencia a la cultura política se hizo imprescindible y el papel que jugó en la narración del proceso de cambio político fue muy notable.

Los postulados funcionalistas, aplicados en una buena parte de las investigaciones sobre la modernización, no fueron la perspectiva más relevante en el análisis del cambio político en España. La asunción de sus tesis en los estudios sociopolíticos estuvo siempre matizada por el peso de una sociología crítica que hacía especial hincapié en la relevancia del conflicto social y que seguía poniendo en un primer plano la incidencia de los factores estructurales en la explicación del cambio político y social.

Los modelos clásicos funcionalistas del cambio político explican la transición como un mero ajuste de la «superestructura» política a una sociedad previamente modernizada en sus dimensiones fundamentales. La democratización se entiende, en las versiones más simplistas, como el momento de «puesta al día» de un sistema político desfasado que ha de responder a las nuevas demandas de mayor especialización, eficacia e institucionalización que le impone la realidad de una sociedad ya modernizada. La incapacidad de hacer frente a este impulso de cambio, es decir, la resistencia a la democratización, supondría de forma inevitable la crisis, quiebra y, finalmente, destrucción del viejo sistema político.

En el caso español, en donde, repito, nunca se aplicó este modelo en su forma pura, las numerosas investigaciones que se habían realizado en años anteriores sobre el impacto de la modernización jugaron entonces un papel importante. Todas estas interpretaciones apuntaban a que ésta había alcanzado ya un estadio muy avanzado y había afectado de forma muy notable a los valores y estilos de vida de amplios sectores de la población. Fue en aquel momento cuando estos mismos trabajos se comenzaron a emplear para afirmar que, a lo largo de la última etapa del franquismo, las transformaciones en la esfera de los valores habían incidido de forma notable sobre la cultura política de los españoles. Podía considerarse, pues, que estaban asentadas unas bases culturales que contribuirían a garantizar no la inevitabilidad pero sí el éxito de un proceso de democratización en España.

Junto a la influencia del proceso general de modernización, ciertos estudios destacaron la importancia de algunos fenómenos concretos que habían impulsado de forma notable el asentamiento de los gérmenes de una nueva cultura política en España. El turismo y la emigración fueron considerados, además de acontecimientos con un indudable impacto en el desarrollo económico, como procesos que sirvieron para transformar de modo significativo los valores de amplios grupos de la población española y como mecanismos de socialización en la cultura y los modos de vida de las democracias occidentales. En esta misma línea, fue entonces cuando comenzó a destacarse la fuerza cada vez 
mayor con la que aparecía en el imaginario colectivo de los españoles la ecuación Europa $=$ bienestar $=$ democracia. Europa, entendida esencialmente como sociedad con altos niveles de bienestar y con grandes esferas de libertad individual y colectiva, se convertiría muy rápidamente en el modelo a imitar por los españoles y, quizá lo que es más importante, en la única salida posible ante el fin inevitable del franquismo. La convicción de que el franquismo no podría sobrevivir al dictador estuvo claramente influida por la exposición de sectores cada vez más amplios de la población española a este «escaparate europeo». Una de las manifestaciones en donde es más perceptible la rapidez de este contagio es el cine español de los años sesenta-setenta.

Pero quizá la contribución más notable de este primer modelo al análisis de las precondiciones culturales del cambio político sea haber prestado atención a los ámbitos de aprendizaje de la vida democrática a lo largo de la última etapa del franquismo. V. Pérez Díaz (1979) fue el autor que apostó más claramente por subrayar la importancia de volver la mirada hacia la «sociedad civil» para observar algunos cambios especialmente significativos a los que confirió una importancia decisiva en la rápida «resocialización» política de los españoles. De acuerdo con sus tesis, la liberalización del franquismo desde finales de los años sesenta habría posibilitado la dinamización de la vida social difundiendo, dentro de ciertos sectores, valores y actitudes imprescindibles para la vida democrática. En concreto, Pérez Díaz se centró en el mundo del trabajo y señaló el impacto de la nueva legislación sindical y, en concreto, de la puesta en marcha de los convenios laborales en la creación de prácticas de negociación y de consenso que serían, unos años después, esenciales para afrontar la transición política. Este proceso de adiestramiento político se habría extendido también a esferas más amplias a través de una cierta revitalización de la vida asociativa. Los cambios en los valores y estilos de vida de los españoles, en las aspiraciones de los empresarios y de los trabajadores, unidos a un proceso de socialización política, habrían ido minando las bases de legitimidad del franquismo y habrían generalizado la convicción de que la democratización era la única salida posible, y la más deseable, una vez desaparecido Franco. Pero, fundamentalmente, habrían ido sentando las bases de la nueva cultura política democrática de los españoles. Tras cuarenta años de autoritarismo las dificultades a superar eran muy numerosas, pero los obstáculos no eran insuperables en la medida en que se contaba con una cultura política favorable que garantizaba tanto la aceptación generalizada del proceso como, en buena medida, la estabilidad de la nueva democracia.

No obstante, la explicación que se convirtió en dominante fue una combinación particular de una determinada versión de la teoría pluralista teñida de algunos de los postulados básicos de la teoría de la elección racional, que había adquirido, ya a mediados de los años setenta, un puesto destacado en la sociología y en la ciencia política. Fue esta interpretación peculiar la que se exportó unos años más tarde para tratar de dar cuenta de la nueva ola democratizadora latinoamericana. El centro de atención de esta corriente fueron los principales 
actores políticos que aparecieron en la escena pública a la muerte de Franco y, más en concreto, las estrategias por medio de las cuales éstos pudieron establecer un pacto básico sobre el que fue posible construir, en un lapso de tiempo muy breve, una democracia comparable a la de los países de nuestro entorno geopolítico y cultural ${ }^{8}$.

Las estrategias y los pactos entre las élites sólo son posibles en la medida en que existan bases socioculturales que hagan posible que la negociación se conciba como la estrategia más beneficiosa para cada una de las partes y que existan refuerzos poderosos (incentivos selectivos los llamaría M. Olson) para el mantenimiento de dicho pacto. En definitiva, el compromiso sólo parece viable si existe un consenso básico acerca de los fundamentos del sistema político y sobre unos objetivos comunes que han de guiar la acción política; ello sólo es factible gracias a unos valores comunes, escasos pero primordiales, que, en definitiva, son los que contribuyen a definir la idea de ciudadanía.

De aquí la enorme importancia que adquirió el estudio de los rasgos principales de la cultura política de los españoles. Si en años anteriores se había comprobado la existencia de unos prerrequisitos culturales mínimos que hacían factible el inicio del cambio político, desde los primeros momentos de la transición se trató de comprobar la solidez de dichas bases y de asegurar que el proceso de difusión, ampliación y profundización de los rasgos esenciales de una cultura política democrática estaba en marcha y adoptaba la dirección adecuada. Este interés explica la considerable expansión y divulgación de las investigaciones de cultura política. Un tema poco estudiado, pero fascinante para comprender el caso español, es el papel que jugó un grupo de sociólogos y politólogos en el diseño de las principales estrategias y en la elaboración de los discursos de las fuerzas políticas que, durante las primeras etapas del cambio, fueron adquiriendo relevancia en la nueva vida democrática. La certidumbre de la existencia de estas bases culturales, junto con algunas ideas básicas acerca de la moderación ideológica de la sociedad española, fueron argumentos determinantes a la hora de marcar cambios fundamentales en el surgimiento de los nuevos grupos y partidos, y en la adaptación de los ya existentes a la nueva situación política.

Las investigaciones sobre la cultura política fueron muy relevantes para la generación de estudiosos que estuvo en primera fila de la investigación sociopolítica a lo largo de la transición y de la consolidación de la democracia. Y esto fue así porque, como he tratado de explicar en los párrafos anteriores, los modelos de interpretación del cambio exigían la introducción de esta herramienta de análisis con el fin de, primero, convencer de la viabilidad de la democratización y, después, dar cuenta de la rapidez y «suavidad» de la misma. A pesar de todo, desde un punto de vista teórico, la cultura política jugó siem-

${ }^{8}$ Una crítica del énfasis excesivo en los actores políticos de los primeros estudios de la transición española se encuentra en Agüero y Torcal (1993). Por su parte, Edles (1998) lleva a cabo un análisis crítico de la «escuela del pacto». 
pre el papel de «categoría residual». Es decir, se empleó para dar cuenta de aquellas lagunas que ni el argumento de la modernización ni los enfoques elitistas lograban colmar a partir de sus presupuestos teóricos. Se utilizó, fundamentalmente, para minimizar los riesgos de desestabilización y para dar cuenta de las bases del pacto entre las élites. Y se usó siempre dentro de la tradición que Welch (1993) denomina el enfoque comparativo para subrayar la similitud de la cultura política española, al menos en sus rasgos esenciales, con la de la mayoría de las democracias occidentales. De este modo, el argumento de la cultura política fue extremadamente funcional para la explicación del cambio político, a costa de perder profundidad en su análisis y de pasar por alto la mayor parte de los aspectos conflictivos tanto en lo que se refiere al proceso de transición como a la reconstrucción de la cultura democrática?

Entre 1975 y 1985 se publicaron unas investigaciones considerables en cuanto a su volumen, y notables en cuanto a su influencia, que se han convertido en los textos de referencia en el estudio de la cultura política en España ${ }^{10}$. A pesar de que existen algunas discrepancias importantes en las interpretaciones de los distintos autores, sus puntos de coincidencia son también numerosos. En primer lugar, el factor común más relevante es haber aplicado la encuesta original de Almond y Verba al estudio del caso español, casi sin modificaciones ${ }^{11}$. Los estudios concedieron una especial atención a la creación de algunas actitudes básicas con respecto a la democracia, entre las que destacan el sentimiento de competencia ciudadana, las dimensiones de legitimidad y eficacia del sistema político y los vínculos entre los ciudadanos y las principales instituciones del sistema político. Por el contrario, la socialización política, un tema al que La cultura cívica había conferido una gran relevancia, suscitó un interés secundario, quizá porque, como tendremos ocasión de comprobar más adelante, la concepción de la socialización política que preconizaba el modelo clásico provocaba dificultades y se hizo necesario introducir modificaciones importantes.

La metodología empleada en estas investigaciones fue exclusivamente cuantitativa y se redujo a la aplicación de encuestas de opinión, apartándose en este punto del modelo original, que había introducido una segunda fase en la

9 Es interesante comprobar cómo, por ejemplo, los estudios de cultura política de este período suelen pasar por alto el problema de la pervivencia y reconstrucción de las culturas políticas nacionalistas o "regionales» en un momento en que uno de los temas principales de la agenda política era la construcción del Estado de las Autonomías. Para un análisis del olvido del caso vasco, véase Edles (1998).

${ }^{10}$ Los trabajos de Linz (1981, 1987), López Pina y Aranguren (1976), López Pintor (1982), Maravall (1982) y Maravall y Santamaría (1989) forman el núcleo central de los estudios de cultura política en estas primeras fases del cambio.

${ }_{11}$ Las similitudes entre el texto de la encuesta de La cultura cívica y los estudios de cultura política realizados por el CIS a comienzos de los años ochenta son notables. A pesar de las lógicas modificaciones debidas a la traducción de la encuesta al castellano y a una cierta adaptación a la realidad española, el grueso de las preguntas sigue sustancialmente la formulación original de Almond y Verba. 
investigación basada en la realización de entrevistas en profundidad ${ }^{12}$. Hay que añadir, además, que todos los autores manejaron una concepción de cultura política como "compartimento estanco», dentro de un modelo formalizado que rara vez trató de establecer relaciones con temas de investigación afines. Es significativo comprobar cómo, mientras que los estudios de valores siguieron desarrollándose, y cuando el estudio de la socialización fue abordado sobre todo desde la psicología social, la reflexión sobre la cultura política apenas mantuvo ninguna línea de comunicación con estas áreas de reflexión. Del mismo modo, se prestó muy poca atención a la indudable influencia de los cambios en la estructura de la familia, en la religión o en el sistema educativo sobre las culturas políticas ${ }^{13}$. En los márgenes de la reflexión sociopolítica sí ha tenido lugar un considerable desarrollo de estos trabajos, pero hasta el momento han sido muy escasos los intentos de construir una perspectiva integradora. La convicción, bastante generalizada, de que la transición política española es un ejemplo casi perfecto de "cambio desde arriba" ha pesado considerablemente en el escaso desarrollo de las investigaciones que tratan de integrar los cambios sociales más importantes con la naturaleza de la transición política ${ }^{14}$.

Existen, no obstante, algunas consecuencias positivas de esta homogeneidad y aislamiento. A costa de perder riqueza en el análisis, la uniformidad de las encuestas ha permitido, con el paso de los años, contar con largas series de datos que facilitan el análisis longitudinal y la comprobación de los elementos de permanencia y cambio de las principales dimensiones de la cultura política $^{15}$.

Al margen de estas similitudes formales, existen también coincidencias en el modo de abordar el estudio de la cultura política, a pesar de que no se puede negar la diversidad de estilos de análisis y algunas divergencias de fondo. Bajo todas estas investigaciones subyace la creencia en una ruptura notable con la vieja cultura autoritaria que caracterizó la vida pública española al menos

${ }^{12}$ Es necesario recordar que Almond y Verba dividieron su investigación en dos partes. En la segunda, tras un primer análisis de los resultados de su encuesta, eligieron una submuestra de los encuestados y llevaron a cabo entrevistas en profundidad con el fin de ahondar en algunos de los temas que consideraban más importantes. En España, la única excepción a este predominio del método cuantitativo en este período fue el trabajo de Maravall, Dictadura y disentimiento politico (1978), cuyo tema de análisis no es el estudio de la cultura política sino el de la oposición al franquismo.

${ }^{13}$ En España no se ha concedido casi importancia al estudio de la "religión civil», uno de los temas directamente vinculados con el concepto tradicional de cultura política que ha sido muy trabajado en Estados Unidos, Gran Bretaña o Francia. El trabajo de S. Giner (1993) constituye una excepción que confirma la regla.

${ }_{14}$ Sin embargo, algunos estudios de sociología de la religión sí han tratado de establecer puentes con el análisis político. Véanse, por ejemplo, Díaz-Salazar (1990), Díaz-Salazar et al. (1990) y Díaz-Salazar y Giner (1993).

15 En los años noventa se han publicado estudios que analizan las tendencias de evolución de la cultura política, aprovechando las ya largas series de datos existentes. Véase, por ejemplo, R. Montero y Torcal (1990). También se ha comenzado a prestar atención a un análisis de cohortes de la cultura política cuyo objetivo es comprobar el cambio generacional y el impacto de la socialiación en la vida democrática. Véase Justel (1992). 
desde el último tercio del siglo pasado. Aquella cultura política que, de acuerdo con las tesis de Linz, jugó un papel relevante en la quiebra de la II República y en el advenimiento del franquismo. Se difundió la convicción de que, por primera vez en la historia de España, se daban las condiciones para sentar las bases de la ciudadanía a escala nacional. Había entonces una clara posibilidad de establecer un pacto que originara un sistema democrático con visos de duración y estabilidad. Esta creencia se concretó en una serie de argumentos que se comprobaron en base a los datos proporcionados por las encuestas de cultura política.

Ante todo, el pacto fundacional presuponía la superación del rencor provocado por la guerra civil, lo que, en cierto modo, implicaba una valoración atemperada del franquismo. Es aquí donde el análisis tuvo que abordar el papel de las memorias colectivas sobre la contienda y el franquismo para evaluar el papel que éstas jugaron en la democratización. Pero, curiosamente, al menos desde la sociología y la ciencia política, el estudio de estas memorias no se realizará hasta algo más tarde (Aguilar, 1995), aunque sí estuviera implícito ante todo en los trabajos de V. Pérez Díaz (1991a, 1991b, 1993). Lo que sí abordaron directamente los estudios de cultura política fue, por un lado, el estudio de la cultura política del franquismo (López Pina y Aranguren, 1976) $y$, por otro, el papel del recuerdo de actitudes y valores democráticos previos a la dictadura. Fue J. M. Maravall (1982) quien planteó la tesis más conocida. Según ésta, a lo largo de todo el franquismo algunos valores, actitudes y recuerdos de la vida democrática habrían permanecido vivos en el seno de las familias y se habrían transmitido entre generaciones. Fueron estos recuerdos los que ayudaron, en los primeros momentos del cambio, a recuperar con rapidez marcos de significados y herramientas para la comprensión y la acción política imprescindibles para la vida democrática.

La consideración del papel de las memorias colectivas en el modelo clásico de la cultura política exigió introducir una rectificación fundamental en uno de sus postulados básicos. El modelo «a la manera de» Almond y Verba se basaba en una concepción parsoniana de socialización entendida como proceso de aprendizaje e interiorización de creencias, actitudes y valores que tiene lugar esencialmente a lo largo de la infancia y del que son agentes fundamentales la familia, la escuela, la Iglesia y, en menor medida, el grupo de pares ${ }^{16}$. Dar cuenta de la posibilidad y del éxito de procesos de democratización suponía atemperar la insistencia en la socialización infantil y dar mayor peso a los procesos de socialización política adulta. Esto es precisamente lo que llevó a cabo el paradigma dominante de análisis del cambio político en España. La transición, desde esta perspectiva, es entendida como un rápido y logrado proceso de «resocialización política» de aquellas generaciones que habían sido educadas y habían visto cómo transcurría buena parte de su vida adulta bajo el franquis-

16 Para una crítica de dicho modelo de socialización y de sus consecuencias en el estudio de la socialización política, véase el trabajo de Percheron (1993). 
mo. Sobre unas bases culturales favorables, establecidas como consecuencia de la modernización y la liberalización del régimen en su última etapa, y con la ayuda de memorias recuperadas de un largo pasado de «normalidad democrática», era posible que tuviera lugar el paso a la democracia.

Los datos de las encuestas de opinión mostraron, desde los primeros momentos del cambio, un juicio benévolo del franquismo junto con una valoración muy positiva de la democracia como sistema político que correspondía a una sociedad moderna y occidental como la española. También parecían señalar el empeño de los españoles por superar el pasado y por marcar las diferencias entre la sociedad contemporánea y aquella en la que se habían dado las condiciones para el estallido de la guerra civil. Sorprende, sin embargo, que el recurso a la memoria como factor explicativo de las bases culturales que posibilitaron el pacto pasara por alto la larga tradición sociológica de reflexión sobre la memoria colectiva. En el estudio de Maravall (1982) los únicos datos que se manejaron al respecto fueron las escasas preguntas que las encuestas de opinión incluyeron sobre el tema y los resultados electorales de las primeras elecciones generales de junio de 1977, que mostraban sorprendentes similitudes con los de las últimas elecciones de la II República de febrero de 1936. Sin embargo, no faltaban las investigaciones sobre la memoria colectiva fuera de nuestras fronteras e, incluso, en España comenzaba a desarrollarse esta línea de trabajo impulsada desde la historia oral. Pero, una vez más, el análisis sociopolítico se vio lastrado por su definición restrictiva de cultura política y por una inseguridad que le empujó a prestar oídos sordos a las aportaciones que estaban realizándose en campos de estudio muy próximos.

Se afirmó, además, que esta postura hacia el pasado se traducía en una actitud ideológica de los españoles esencialmente moderada, subrayándose el escaso peso de las ideologías más extremistas tanto a la izquierda como a la derecha del espectro político. La moderación se combinaba, además, con un cierto pragmatismo político y con actitudes reformistas muy difundidas entre la población. La confianza en la exactitud de la tesis de la moderación de los españoles fue adoptada con mayor o menor prontitud por todos los partidos políticos, en especial por aquellos que habían constituido la oposición al franquismo, y tuvo un peso determinante a la hora de provocar cambios muy significativos en algunos de sus presupuestos ideológicos, en sus discursos y en el diseño de sus estrategias. Los analistas políticos presentaron los resultados de las elecciones generales de junio de 1977 como prueba concluyente de la exactitud de dicha tesis.

Por su parte, las actitudes reformistas del grueso de la población se concretaban, según estos estudios, en una particular concepción de la democracia. Este sistema, el más conveniente para España a la salida del franquismo, era entendido por la gran mayoría en términos esencialmente liberales. Es decir, la democracia, cuyo referente máximo siguió siendo en todo momento Europa, aparecía en las encuestas como un sistema que garantiza las libertades individuales y colectivas, más que como uno que ha de tender a la igualdad de todos 
los ciudadanos. No obstante, este sesgo liberal se atemperaba con una alta valoración del papel del Estado como institución encargada de impulsar la igualdad social y con actitudes muy favorables a la introducción de reformas sustanciales que operaran en este sentido. Algo más tarde, esta supeditación de los ciudadanos al Estado como promotor de la igualdad y el bienestar ha sido criticada en trabajos que abordan el estudio de la cultura económica y que mantienen tesis próximas a ciertas vesiones de la ideología neoliberal ${ }^{17}$. La debilidad de la sociedad civil en España y el escaso arraigo de la mentalidad empresarial se debería a la secular dependencia de los españoles a un Estado parternalista; una sumisión que daría cuenta de algunas de las principales debilidades de la vida pública en nuestro país.

La fortaleza de los argumentos de la socialización política adulta no significó que estos estudios no tuvieran que tratar el problema del peso del franquismo en la construcción de la cultura política democrática. Al margen de algunos trabajos que abordaron directamente el análisis de la cultura política franquista (López Pintor y Aranguren, 1976), el reconocimiento de la inevitable huella que habían dejado las largas décadas de ausencia de libertades y de vacío de vida pública se concretó en dos argumentos principales. Por un lado, se recordó la persistencia del cinismo político que ya algunos años antes J. Linz había apuntado como característica sobresaliente de la cultura política tradicional española. Linz había retomado el argumento en los mismos términos que, ya a finales de la década de los cincuenta, S. M. Lipset (1959) había planteado al estudiar las bases sociales de los regímenes democráticos. Para Lipset, la estabilidad de los regímenes políticos dependía de la particular relación que en cada momento y caso concreto se establecía entre su eficacia y su legitimidad. El cinismo político, para Linz, consistía en aquella particular disposición en la que los ciudadanos establecen una distancia desmesurada entre una alta legitimidad del sistema político y una eficacia muy baja del mismo ${ }^{18}$.

Siguiendo a este autor, los trabajos de cultura política explicaron la baja eficacia atribuida al sistema político como consecuencia del peso de la tradición histórica del Estado en España, que siempre había provocado un alejamiento considerable entre los ciudadanos y las esferas de toma de decisión política. No obstante, esta baja eficacia se contradice con el importante papel que los españoles atribuían al Estado en aquel momento, y siguen haciéndolo hoy en día, como encargado de limitar las desigualdades sociales. Por su parte, la alta legitimidad de la democracia sirvió para mantener la confianza en su estabilidad incluso en aquel período en el que siguió planeando el fantasma de

17 Éste es el caso, por ejemplo, de algunos trabajos de V. Pérez Díaz publicados a comienzos de los noventa. En concreto, véase Pérez Díaz (1991a, 1991b, 1993).

${ }^{18}$ Se trataría de la situación inversa a la que caracterizó la cultura política de la RDA durante largas décadas tras el fin de la Segunda Guerra Mundial. En el caso de Alemania Occidental se hallan altos niveles de eficacia atribuida al sistema, mientras que éste no logra nunca una alta legitimidad. 
la desestabilización y el golpe de Estado. Finalmente, el argumento del cinismo político se empleó también para explicar algunas de las diferencias fundamentales de la cultura política de los españoles en comparación con la de los ciudadanos de las viejas y estables democracias occidentales.

Dos fueron los principales rasgos de diferenciación subrayados y ambos se atribuyeron a la huella del franquismo, a pesar de que se confiaba en que la práctica en la vida democrática iría limando esta distancia: primero, los bajos niveles de competencia política, uno de los elementos esenciales que definen la cultura cívica en el modelo clásico; en segundo lugar, los bajos niveles de aquellas actitudes y valores esenciales para construir las bases de la participación política. En este último punto cabe destacar la debilidad de la identificación partidista en España y los bajísimos niveles de afiliación a cualquier tipo de organización de carácter político ${ }^{19}$.

Algunos de los exponentes de la «escuela del pacto» emplearon las evidencias que proporcionaban los estudios de cultura política para desarrollar un marco de explicación de la transición española como "cambio desde arriba" en la que el juego de las élites y su libertad de maniobra para lograr los pactos fundacionales se habrían visto favorecidos por la escasísima participación de los españoles ${ }^{20}$. Por el contrario, un grado de movilización más alto hubiera puesto en peligro la suavidad, rapidez y éxito del proceso ${ }^{21}$. En cualquier caso, dejando a un lado la funcionalidad de la tesis de la desmovilización y obviando entrar en el tema de fondo de si logró dar cuenta de la realidad de los hechos, me interesa únicamente resaltar la confianza que subyacía bajo todo este discurso en la rápida recuperación de la vida participativa por medio de la práctica en la vida democrática.

La tesis de la desmovilización fue matizada ya en estos momentos por una serie de autores que insistieron en la necesidad de tomar en consideración el peso de los factores estructurales y de las "presiones desde abajo» en la explicación del cambio. La política de la transición, de J. M. Maravall (1982), fue pionera en la defensa de una perspectiva que trataba de combinar los factores estructurales, la movilización popular y las estrategias de las élites políticas como marco para la interpretación rigurosa de la democratización española. No puede olvidarse que la mayor parte de los estudios de la transición española que fueron publicándose a lo largo de los años ochenta adoptaron una pers-

19 Acerca de las características de la identificación partidista en España, véase Del Castillo (1990).

20 Esta tesis fue defendida, sobre todo, por López Pintor (1982). Pero incluso muy recientemente siguen publicándose trabajos que apoyan esta postura. En concreto, puede verse Sastre (1998).

${ }^{21}$ Ya en plena década de los noventa, esta tesis ha sido recuperada para explicar las diferencias entre el caso español y los procesos de democratización en Europa del Este, que son definidos como ejemplos máximos de "transiciones desde abajo» en donde es imprescindible tomar en consideración el papel de los movimientos políticos, es el origen, desarrollo y resultados del cambio. Entre la numerosa literatura sobre el tema pueden consultarse Oberschall (1996) y Zdravomyslova (1996). 
pectiva muy similar a la defendida por Maravall, al tiempo que todos ellos incorporaron el estudio de la cultura política en un lugar destacado ${ }^{22}$.

Para concluir, la contribución más significativa de este conjunto de trabajos es la admisión generalizada de que, al inicio de la transición, los rasgos básicos de la cultura política de los españoles eran esencialmente comparables a los de los ciudadanos de las democracias occidentales ${ }^{23}$. Se confiaba, además, en que el proceso de socialización política adulta, es decir, la práctica en la vida democrática, permitiría colmar las brechas que, en algunos aspectos concretos, seguían diferenciándonos de Europa y continuaban impidiendo que, en sentido estricto, se considerara la cultura política de los españoles como una auténtica «cultura cívica».

\section{RASGOS MÁS RELEVANTES DE LOS ESTUDIOS SOBRE LA CULTURA POLÍTICA DE LOS ESPAÑOLES EN LOS AÑOS OCHENTA Y NOVENTA}

La mayor parte de las investigaciones sobre la cultura política de los españoles a lo largo de los años ochenta y en la década posterior siguieron, en lo esencial, las líneas trazadas por los estudios realizados en el momento de la transición política y la consolidación de la democracia. Sin embargo, la rutinización de la vida democrática dio lugar a un cierto cambio de énfasis en la agenda de temas de investigación.

En primer lugar, se insistió en la estabilidad y en la ausencia de cambios apreciables en las dimensiones básicas de la cultura política. En este sentido, los trabajos han tendido a destacar el mantenimiento de los altos niveles de legitimidad de la democracia incluso en los momentos en los que los cambios de gobierno o las crisis de ciertas instituciones podrían haber provocado una merma del apoyo popular a la democracia. Pero, al tiempo, se reconoció también que las optimistas previsiones del impacto de la socialización política adulta en la vida democrática no parecen haberse cumplido tan fácilmente como se pensaba. En primer lugar, se ha constatado la persistencia del cinismo político y, en concreto, de la baja eficacia que se atribuye al sistema político aun en momentos en que otro tipo de indicadores daban cuenta de un alto nivel de eficacia en la gestión gubernamental. En segundo lugar, se ha resaltado la inexistencia de cambios significativos en las bases de la participación

${ }^{22}$ Los estudios colectivos más conocidos sobre la transición fueron dirigidos por Giner (1990), J. F. Tezanos (1989) y Cotarelo (1992). Dentro de este grupo también puede incluirse la obra coordinada por O’Donnell y Schmitter (1986), que, aunque tiene como objeto el análisis más amplio de los procesos de transición, dedica una parte al estudio de los procesos de democratización en el Sur de Europa, y en concreto en España.

${ }^{23}$ La comparación de los datos de las encuestas realizadas en España con los que proporcionaban los Eurobarómetros tuvo una especial importancia para fundamentar estas conclusiones. 
política, al menos en lo que se refiere a los canales convencionales de participación en la vida pública. La identificación partidista ha seguido siendo muy débil y los niveles de afiliación a las organizaciones políticas han continuado bajo mínimos. Desde mediados de los años ochenta se asiste, además, a un cambio significativo en la interpretación de la abstención. La ausencia de participación electoral, que, hasta el momento, había sido entendida o bien como simple «abstención técnica» o como un comportamiento privativo de aquellos sectores de la sociedad menos educados o más «alejados» del sistema político, ha dejado paso a argumentaciones que comienzan a apuntar la incapacidad del sistema político por generar o avivar cauces participativos que enriquezcan la calidad de la vida pública española ${ }^{24}$. Este nuevo énfasis se percibe también en el modo en que el "desencanto» comenzó a explicarse como un elemento más dentro de un proceso más amplio de crisis de la «vieja política» que afecta, sobre todo, a los canales tradicionales de participación política. Los significativos cambios en la participación y la acción colectiva que han tenido lugar en España a lo largo de la década de los noventa, concretamente el «renacimiento» de nuevos y viejos movimientos sociales y el auge de las ONGs y de otras formas de voluntariado, han provocado que se establezca una vía de comunicación entre los estudios de cultura política y las investigaciones sobre la acción colectiva.

Por último, cabe destacar como otro de los rasgos comunes a la reflexión de este período el modo en que se ha subrayado el mantenimiento de elevados sentimientos de europeísmo en España. Incluso tras la incorporación de España a la UE, una vez cumplido uno de los principales logros que animaron el proceso de democratización, Europa no constituyó nunca un problema político, un objeto de controversia política. Sólo algo más tarde, ya casi finalizada la década de los noventa, han comenzado a surgir algunos signos que apuntan a la incorporación del tema europeo en la agenda política, por lo que habrá que esperar todavía unos años para ver el modo en que dicho cambio se traduce en la cultura política española.

Las encuestas de opinión han seguido constituyendo el método de investigación fundamental para los estudios de cultura política, aunque en este período comienzan a aparecer algunas excepciones a esta tónica general que aplican una metodología de tipo cualitativo para ahondar en algunos aspectos específicos del problema. La investigación de R. del Águila y R. Montoro (1982) sobre la construcción del discurso político de la transición, basada en un análisis de los diarios de sesiones de la Comisión Constitucional, es uno de los pocos trabajos que se inscriben dentro de la tradición interpretativa de la cultura política. Lamentablemente, su interesante aportación no parece haber tenido continuidad en el análisis sociopolítico de los años más recientes. En una línea similar, J. E. Rodríguez Ibañez (1987) publicó un análisis de la cul-

${ }^{24}$ Ésta es una de las principales conclusiones del estudio de Justel (1993) sobre la abstención electoral en España. A este respecto también pueden consultarse Virós (1994) y Morán (1997a). 
tura política basado en entrevistas en profundidad. Dos islotes aislados en medio de un mar de encuestas de opinión.

Existe, además, otra importante línea de continuidad entre los primeros estudios de la cultura política y la nueva "generación" de trabajos que se concreta en el mantenimiento de una visión de la cultura política como una construcción analítica de carácter homogeneizador. Un rasgo destacable del empleo de la cultura política en los estudios españoles es su escasa atención a la existencia de "subculturas» políticas significativas, y ello es especialmente sorprendente si se considera que uno de los principales retos de la democratización española fue el reconocimiento y el intento de resolución del problema de las nacionalidades. Sin embargo, tanto en la primera como en la segunda oleada de la reflexión sobre la cultura política se siguió operando dando por sentada la existencia de algo parecido a una cultura política global.

Es cierto que desde los años ochenta comenzaron a publicarse algunos trabajos sobre la construcción y la naturaleza de culturas políticas en las «nacionalidades históricas» ${ }^{25}$. Sin embargo, a pesar del énfasis que el modelo clásico confería a la confrontación entre casos, no existen grandes estudios de ámbito estatal que tengan un propósito comparativo ${ }^{26}$. Tampoco se ha prestado suficiente atención al impacto de las grandes líneas de fractura que recorren la estructura social española en la constitución de posibles subculturas políticas específicas. Únicamente algunos trabajos aislados han empezado a trabajar en la relación entre cambio generacional y transformaciones en la cultura políti$\mathrm{ca}^{27}$, pero, por ejemplo, los estudios sobre valores y actitudes políticas de la juventud siempre parecen haber sido realizados «al margen» de las investigaciones convencionales de cultura política y han sido escasamente empleados por los estudiosos para apoyar sus reflexiones ${ }^{28}$. Un campo en donde sí se ha avanzado sustancialmente en la consideración de «subculturas políticas de la juventud» ha sido el de la aplicación de las tesis de R. Inglehart sobre la extensión de los valores postmaterialistas en las nuevas generaciones y su impacto en la vida política de las sociedades modernas ${ }^{29}$.

${ }^{25}$ Los trabajos de Llera $(1989,1994)$ sobre el País Vasco o el de Cabrera (1988) sobre Galicia son ejemplos de este tipo de investigación. Las encuestas preelectorales que el CIS ha venido realizando en vísperas de todas las elecciones autonómicas incluyen algunas preguntas relativas a la cultura política. Sin embargo, estas fuentes han sido escasamente utilizadas a efectos comparativos.

${ }^{26}$ Salvo algunos estudios aislados del CIS, la mayor parte de las encuestas de opinión no cuentan con una muestra suficiente para ser representativa a nivel autonómico. De este modo, las comparaciones entre regiones, y entre éstas y la "cultura nacional», son extremadamente difíciles.

${ }_{27}$ El mencionado trabajo de Justel (1993) constituye la principal referencia de este interés.

${ }_{28}^{28}$ No obstante, todos los Informes de la Juventud realizados por el Instituto de la Juventud incluyen datos de interés.

29 Díez Nicolás ha sido el encargado de llevar a cabo en España la encuesta internacional de valores, coordinada por R. Inglehart. Por su parte, Torcal $(1989,1992)$ ha aplicado el esquema de Inglehart tratando de comprobar la validez de las tesis de la extensión de los valores postmaterialistas en el caso español. 
La misma tónica de escasa preocupación por el análisis de subculturas políticas específicas se hace patente cuando se considera el reducido desarrollo de estudios sobre la relación entre mujer y cultura política, un hecho sorprendente habida cuenta de la importancia cada vez mayor de la perspectiva de género en la investigación social en nuestro país ${ }^{30}$. Por último, es también notable que la primera oleada de estudios de cultura política no haya abierto el camino para un examen sistemático de las fracturas entre culturas políticas de élites y culturas políticas de "masas», ni que tampoco se haya avanzado en la investigación sobre la construcción de culturas políticas de organizaciones como los partidos políticos y los sindicatos ${ }^{31}$ y sobre su impacto tanto en las dificultades de institucionalización del nuevo sistema de partidos en España como en el estilo político que imponen a la vida pública en nuestro país. En definitiva, la mayoría de los estudios que se han ido publicando a lo largo de los últimos diez o quince años no abordan de forma satisfactoria ni la relación entre desigualdad social y construcción de las culturas políticas, ni tampoco extienden la reflexión al surgimiento y el modo en que operan las culturas específicas de organizaciones e instituciones particularmente relevantes a la hora de considerar algunas de las singularidades de la rutinización de la vida democrática.

Esta limitada capacidad de salir de los estrechos límites en los que la definición restrictiva de cultura política se había encerrado es también patente cuando se consideran las mínimas innovaciones de carácter teórico o metodológico que han introducido las investigaciones más recientes frente a las de la primera ola. Salvo en lo que supone una mayor sofisticación en las técnicas de análisis, los estudios de cultura política no parecen haber logrado superar el marco que la herencia intelectual y las exigencias del proceso democratizador impusieron a los trabajos. La característica principal de la investigación de este período es la aplicación de la perspectiva de la cultura política a determinadas áreas de análisis, al tiempo que continúa la acumulación de datos que hace cada vez más asequible el análisis longitudinal.

En lo que respecta al primer nivel, cabe destacar el considerable desarrollo de los estudios electorales desde los años ochenta. El interés por la participación electoral está íntimamente asociado con la reflexión en torno a la constitución del sistema de partidos y sus dificultades. Se trata de trabajos de sociología del electorado, en los que el análisis de las dimensiones de cultura políti-

${ }^{30}$ El Instituto de la Mujer impulsó ya hace unos años la realización de explotaciones de los estudios del CIS de cultura política desde una perspectiva de género. Sin embargo, no tengo conocimiento de que el resultado de estos análisis haya sido publicado. Ello contrasta, por ejemplo, con la mayor atención prestada a campos de reflexión afines como el estudio de la participación política de las mujeres (Astelarra, 1990) o la presencia de las mujeres en la élite política (García de León, 1982, 1994)

${ }^{31}$ Los estudios sobre las culturas políticas de las organizaciones, y en concreto de los partidos, han tenido un considerable desarrollo en otros ámbitos académicos y, particularmente en el francés. M. Lazar (1990), Molinari (1991) o Verret (1988), por ejemplo, son una referencia clara a la hora de analizar la cultura política de la izquierda en Francia, y más concretamente la del Partido Comunista Francés. 
ca posee una particular relevancia. De este modo, se continúa ahondando en algunas de las dimensiones clásicas de la cultura política como son los sentimientos de competencia ciudadana, la identificación partidista o los canales a través de los cuales se recibe la información política y el modo en que los ciudadanos la emplean a la hora de formar sus elecciones ${ }^{32}$. Dentro de esta línea de reflexión va adquiriendo cada vez mayor relevancia la preocupación por el análisis de la abstención electoral. Tal y como he mencionado con anterioridad, se percibe desde mediados de los ochenta un cambio de óptica que comienza a atribuir la persistencia de ciertas formas de apatía política a la incapacidad de los principales actores e instituciones de sentar las bases de una vida

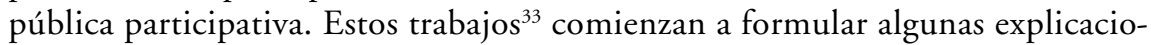
nes del fracaso relativo, o de la extremada lentitud, del proceso de socialización política adulta.

Estrechamente asociado con las investigaciones de sociología electoral se percibe, también desde mediados de los ochenta, un renovado interés por el estudio de la participación política. También en este caso existe una traslación desde la esperanza de que un proceso de socialización «natural» fuera sentando las bases para una mayor implicación de los ciudadanos en la vida pública a una percepción de la creciente importancia de nuevos ámbitos de implicación política. De este modo, reconocer la persistencia de la debilidad de las culturas políticas participativas en las esferas tradicionales de la vida política se contrapone al resurgimiento de «viejos» movimientos sociales y a la aparición de otros nuevos en la escena pública. Las tesis del abandono de la antigua esfera de la política y de la revitalización de la sociedad civil no ocultan, sin embargo, el impacto que poseen estos nuevos ámbitos de participación y acción colectiva tanto en la agenda política como en las estrategias de los viejos actores. El volumen de este tipo investigaciones comienza ya a ser notable; se trata, en su gran mayoría, de trabajos que se ubican en las fronteras de una concepción restrictiva del argumento de la cultura política y que, además, abandonan el enfoque y la metodología convencionales. Pero una lectura atenta de los mismos proporciona interesantes contribuciones a lo que comienza a apuntarse como una nueva óptica de trabajo más enriquecedora en torno a las múltiples culturas políticas de la sociedad española ${ }^{34}$.

Si hasta este momento me he centrado fundamentalmente en la aparición

${ }^{32}$ La literatura sobre sistemas de partidos es muy abundante. Algunos trabajos que destacan por introducir el tema de la cultura política son el citado de Del Castillo (1990) sobre la identificación partidista y Del Castillo (1995). Una buena compilación de reflexiones acerca de la transformación de la comunicación en España puede encontrarse en el número 57 de la REIS (1992), que fue coordinado por Martín Serrano. De especial interés para la reflexión sobre la relación entre cultura política y medios de comunicación son los artículos de Díez Nicolás, Morán, Gaitán y Rodríguez Lara.

33 En la nota 24 se encuentran las referencias de estas publicaciones.

${ }^{34}$ Entre otros trabajos, pueden destacarse los de Funes (1998), Alonso (1995) y Tejerina (1992, 1995). Algunos de estos autores comienzan también a cuestionar la tesis de la desmovilización de la sociedad española durante la transición. 
de algunos temas «nuevos» de investigación que afectan a la reflexión sobre la cultura política, no puedo dejar de reconocer que existen también importantes líneas de continuidad. Sobre todo, no debe olvidarse que a lo largo de la última década se mantiene, o incluso aumenta, la atención por el estudio de las bases de legitimidad y de estabilidad de la democracia española. Se trata de un tema recurrente, sin duda muy influido por la relevancia que los medios de comunicación y la opinión pública han seguido prestando a los riesgos de una crisis política, incluso tiempo después de haberse superado los fantasmas de la desestabilización y del golpe de Estado. Estamos hablando de una línea de reflexión que se había iniciado a comienzos de los ochenta con el discurso en torno al "desencanto»" ${ }^{35}$. Este término fue acuñado, ya a comienzos de los ochenta, en medios intelectuales y artísticos ${ }^{36}$ para reflejar la apatía y el alejamiento de algunos grupos significativos de la esfera de lo público y su retraimiento al ámbito privado en un momento en el que, una vez finalizado el cambio político, la sociedad española se embarcó en una loca carrera de consumismo y de «retorno a lo privado».

Desde las Ciencias Sociales se dieron dos explicaciones a este fenómeno. Por un lado, se argumentó que el desencanto era simplemente el momento que señalaba la rutinización de la democracia; algo parecido a un «bajón» lógico y previsible que se produce tras un período de compromiso e implicación política muy intensos. Por ello, se argumentó que se trataba de un fenómeno pasajero y, sobre todo, común a todos los procesos de democratización ${ }^{37}$. Pero algunos estudios proporcionaron una interpretación distinta. Según éstos, se trataría de un fenómeno más complejo en el que intervienen, en primer lugar, las inercias tradicionales del sistema político español, que ha sido y sigue siendo incapaz de disminuir la distancia entre la esfera de lo público y la de la vida ciudadana. Estas debilidades de la democracia española se entienden como «costes» del particular modo en que se llevó a cabo la transición, como el precio a pagar por haber garantizado la rapidez y la suavidad de la democratización. Por último, se destaca la influencia del cambio generacional y la importante transformación de los valores de las cohortes más jóvenes ${ }^{38}$. Se trata de argumentos con notables conexiones con las tesis de la extensión de los valores postmaterialistas en la sociedad española y con los estudios sobre la naturaleza de las nuevas formas de participación que han tenido un especial arraigo entre los jóvenes.

Los estudios de cultura política del último decenio han transitado entre la continuidad y la apertura a nuevos temas de análisis. Tomados en su conjunto,

35 Los trabajos de McDonough et al. (1988), Paramio (1985) o Paramio y Pérez Reverte (1980), Pérez Díaz (1991) y J. R. Montero (1992) son buenos ejemplos de este interés.

${ }^{36}$ La película de J. Chávarri El desencanto refleja de un modo muy inteligente cómo afectó este fenómeno a una generación.

37 Ésta es la tesis que mantiene Montero (1990, 1991, 1993).

${ }^{38}$ La formulación de estos argumentos puede encontrarse en Virós (1994) y Pérez Díaz (1991). 
bien podrían señalarse dos grandes características en el modo en que enfocan su tarea. Ante todo, cabe destacar la aparición de obras y artículos que tratan de compilar los principales resultados de trabajos anteriores pero reforzando el interés por el análisis longitudinal. En estas revisiones se percibe un cierto esfuerzo por una puesta al día de los problemas teóricos y metodológicos. Existe, pues, un reconocimiento de que la sociología y la ciencia política españolas tienen el deber de comenzar a afrontar la discusión teórica sobre la naturaleza y aplicación del concepto de cultura política al estudio de los principales rasgos de la sociedad actual. En estas obras se encuentran también los primeros atisbos de un cambio del objeto de estudio desde aquella definición tan amplia de «la cultura política de los españoles» a la consideración de algunos temas de estudio más concretos como, por ejemplo, el impacto de los medios de comunicación o las culturas políticas de las élites ${ }^{39}$.

Por otro lado, no puede olvidarse la activa participación de algunos de los autores que más habían trabajado en la primera oleada de estudios en el foro más amplio de los procesos de cambio político y las nuevas olas de democratización. Quizá con la excepción de los estudios iberoamericanos, se trata de investigaciones aisladas, de estudios de caso que han considerado que la base cultural del cambio político continúa siendo una perspectiva relevante en la interpretación de los procesos de democratización ${ }^{40}$.

\section{EN LAS FRONTERAS DE LA CULTURA POLÍTICA}

En los años ochenta, el «retorno de la cultura a un primer plano» ha abogado por una ampliación del término cultura y por profundizar en las posibilidades que abre esta perspectiva para la investigación de los procesos de cambio social y de la acción colectiva ${ }^{41}$. Se trata de un movimiento en consonancia con la puesta en cuestión de la validez de las fronteras establecidas entre las Ciencias Sociales y con la apuesta por perspectivas de análisis cada vez más multidisciplinares. A lo largo de este artículo he pasado revista a líneas de investigación y trabajos de cultura política desde una concepción ciertamente estrecha de la misma. Sin embargo, completar una visión panorámica del «estado de la cuestión» exige incluir temas y ámbitos de investigación que, en su mayoría, han ido desarrollándose al margen de las investigaciones centrales de esta perspectiva pero que han tenido una clara influencia en algunos de los cambios de

39 Destacan, en este sentido, Montero y Torcal (1990), el número monográfico de la revista Documentación Social (1988), Morán y Benedicto (1995), Del Castillo y Crespo (1997).

40 Además del impulso que, desde la Universidad de Salamanca, M. Alcántara ha dado a las investigaciones sobre la cultura política de las élites en Iberoamérica (véase Martínez, 1997), pueden señalarse los trabajos de González sobre la transición húngara (1997) y de Aguilera del Prat sobre la cultura política de la Liga Norte en Italia (1997).

${ }^{41}$ Una recolección de algunos artículos significativos que apuntan en esta dirección puede encontrarse en el número monográfico de Zona Abierta (1996). 
perspectiva a los que me he referido en anteriores apartados. Unos trabajos con los que las ópticas más convencionales han abierto recientemente un diálogo que tiene todos los visos de llegar a ser extremadamente fructífero en un futuro próximo.

Sin pretender abarcar todas las áreas de investigación con las que se ha ido estableciendo esta comunicación, voy a dedicar la última parte del texto a una somera presentación de las que considero más relevantes. En primer lugar, destacan los estudios sobre las bases sociales del nacionalismo desarrollados desde las «nacionalidades históricas». Aunque operan desde diferentes perspectivas de análisis, estos trabajos coinciden en resaltar la relevancia de los fundamentos culturales y los valores en la redefinición de las ideologías nacionalistas, en los modos en que éstas operaron en el momento de la construcción de una nueva esfera pública democrática y, finalmente, en el surgimiento de nuevos actores políticos y en la adaptación de los viejos a las nuevas circunstancias políticas. A mi juicio, es muy relevante la línea de trabajo marcada por un grupo de científicos sociales en el País Vasco que, desde los años ochenta, han apostado por una aproximación diversa al estudio de la cultura política en su reflexión acerca de los fundamentos de la "identidad nacional vasca»" ${ }^{42}$. Ésta es también la línea de argumentación que sigue el libro de L. Edles (1998) en su análisis de los marcos culturales y simbólicos en los que tuvo lugar la transición política española. Edles aplica al caso español una perspectiva de análisis cultural más próxima a la tradición interpretativa de la cultura política, que descansa en una definición de la misma como conjunto de discursos, lenguajes, mitos y símbolos que contribuyen a crear los marcos de significados dentro de los cuales adquieren sentido los comportamientos individuales y las acciones colectivas. Su trabajo presta una especial atención a la excepcionalidad del País Vasco a lo largo del proceso democratizador español.

Hemos asistido también recientemente a un notable desarrollo de la historia cultural, que en España ha tenido una estrecha vinculación con los estudios de acción colectiva y con la importancia atribuida por algunos de sus estudiosos a los recursos culturales en el surgimiento o inhibición de la movilización. Los trabajos de autores como J. Álvarez Junco, M. Pérez Ledesma o R. Cruz representan, en este sentido, un diálogo fecundo entre la historia y las Ciencias Sociales. Pero, además, suponen la aplicación de algunas de las preocupaciones de los estudios de cultura política a la investigación histórica de la España contemporánea ${ }^{43}$.

La reflexión en torno a las bases de la ciudadanía constituye también otro terreno fronterizo en el que se están empezando a producir contribuciones

${ }^{42}$ Los trabajos de Pérez Agote $(1987,1988)$, Gurrutxaga $(1985,1996)$ y Unzueta (1988), entre otros, son un buen ejemplo de este campo de trabajo. Para un análisis de las diferencias entre el discurso acerca de la "cultura política de los españoles» con el que defienden estos autores, véase Morán (en prensa).

${ }_{33}$ Una magnífica muestra de este diálogo puede encontrarse en el libro coordinado por Cruz y Pérez Ledesma (1997). 
relevantes para el argumento de la cultura política. Si bien el debate central sobre los fundamentos y la naturaleza de la ciudadanía en las sociedades contemporáneas ha tenido lugar esencialmente en el campo de la filosofía política, de la ética y del derecho, se ha comenzado a sentir su peso en la investigación social aplicada en los últimos años. No hay que olvidar que la transición española y la rutinización de la democracia son también el período en el que tiene lugar el asentamiento de las bases de la ciudadanía junto con la construcción de los cimientos del Estado de bienestar. En los últimos años han comenzado a publicarse en nuestro país algunos trabajos en los que se percibe la voluntad de abordar este estudio ${ }^{44}$. Por último, no deseo pasar por alto que desde la antropología también se han publicado algunos trabajos interesantes que participan también de este renovado debate en torno al concepto de cultura, aplicando el concepto de cultura política en trabajos de antropología política o antropología urbana.

\section{BIBLIOGRAFÍA}

NotA: A continuación se presentan aquellas publicaciones con las que he trabajado a la hora de presentar el panorama de los estudios de cultura política en España, así como algunos textos de referencia que considero fundamentales. Pero toda bibliografía es, por definición, incompleta, y más aún en un campo con fronteras tan imprecisas como éste.

AA.VV. (1970): Informe sociológico sobre la situación social en España, dirigido por A. de Miguel et al., Fundación FOESSA, Madrid: Euroamérica.

- (1975): Estudios sociológicos sobre la situación social de España, 1975, dirigido por A. Carrión Garzarán et al., Fundación FOESSA, Madrid: Euroamérica.

- (1981): Informe sociológico sobre el cambio político en España, 1975-1981, dirigido por J. J. Linz et al., Fundación Foessa, Madrid: Euroamérica.

- (1983): Informe sociológico sobre el cambio social en España, 1975-1983, dirigido por F. Murillo Ferrol, Fundación FOESSA, Madrid: Euroamérica.

Adell, R. (1988): «Movimientos sociales y cultura política», Documentación Social, núm. 73, pp. 123-145.

AgüERo, F., y TORCAL, M. (1993): «Élites, factores estructurales y democratización», Revista de Estudios Políticos, núm. 80, pp. 329-350.

ÁGuila, R., y Montoro, R. (1984): El discurso politico de la transición, Madrid: CIS.

Aguilar, P. (1995): Memoria y olvido de la Guerra Civil española, Madrid: Alianza Ed.

- (1996): «La amnesia y la memoria. Las movilizaciones por la amnistía en la transición», en R. Cruz y M. Pérez Ledesma (eds.), Cultura y movilización en la España contemporánea, Madrid: Alianza Ed.

Aguilera del Prat, C. R. (1992): «¿Hacia una disolución de las culturas de partido en la Europa occidental?», Sistema, núm. 107, pp. 35-54.

- (1997): "Valores sociales de mercado en la cultura política de la Liga Norte», en P. del Castillo e I. Crespo (eds.), Cultura Politica, Valencia: Ed. Tirant lo Blanch, pp. 155-184.

Alabart, A.; García, S., y Giner, S. (1994): Clase, poder y ciudadanía, Madrid: Ed. Siglo XXI.

${ }^{44}$ En concreto, Alabart et al. (1994), Benedicto (1997 y en prensa). 
Alexander, J. (1982): Theoretical Logic in Sociology. Vol. I: Positivism, Presuppositions, and Current Controversies, Berkeley: University of California Press.

Almond, G., y Verba, S. (1970): La cultura civica, Buenos Aires: Ed. Euroamérica (e.o., 1963).

- (eds.) (1980): The Civic Culture Revisited, Boston: Little Brown.

ALONSO, L. E. (1995): "Crisis y transformación de los nuevos movimientos sociales en un entorno postfordista», en P. del Castillo (ed.), Comportamiento politico y electoral, Madrid: CIS, cap. 16.

Alted, A. (1990): «La cultura política del Republicanismo liberal español en el exilio. Un ensayo de caracterización a través de la Revista Ibérica (1953-1974)», Cuadernos Republicanos, núm. 3, pp. 35-53.

Asensio, M. A. (1973): «Ciencia Política y cultura política», Revista Española de la Opinión Pública, núm. 33, pp. 111-128.

Astelarra, J. (ed.) (1990): Participación politica de las mujeres, Madrid: CIS.

BACHraCh, P. (1967): The Theory of Democratic Elitism. A Critique, Boston: Little Brown.

BenEDICTO, J. (1989): «Sistemas de valores y pautas de cultura política predominantes en la sociedad española 1976-1985", en J. F. TEZANOS et al., La transición democrática española, Madrid: Ed. Sistema.

- (1993): «¿Espectadores o Actores Potenciales? El debate sobre los sistemas de creencias políticas de los ciudadanos", Revista de Estudios Políticos, núm. 80, pp. 271-295.

- (1997): «Las bases culturales de la ciudadanía democrática en España», en P. del Castillo e I. Crespo (eds.), Cultura Política, Valencia: Ed. Tirant lo Blanch, pp. 223-258.

- (en prensa): "Démocratie, citoyenneté et culture politique en Espagne», en M. Lazar y D. Cefaï (eds.), Cultures Politiques, París: PUF.

Benedicto, J., y RequenA, M. (1988): Relaciones interpersonales, actitudes y valores en la España de los ochenta, Madrid: CIS.

Berrio, F. J. (1994): «Cultura política de los españoles», en Cuadernos de Estrategia, núm. 68, pp. 157-183.

Botella, J. (1992): «La cultura política en la España democrática», en R. Cotarelo (ed.), Transición política y consolidación democrática. España (1975-1986), Madrid: CIS, pp. 121-136.

- (1997): «En torno al concepto de cultura política: dificultades y recursos», en P. del Castillo e I. Crespo (eds.), Cultura Política, Valencia: Ed. Tirant lo Blanch, pp. 17-38.

Cabrera, J. (1988): "Consideraciones para el estudio de la identidad y la cultura política en Galicia», Cuadernos de Estudios Gallegos, vol. 36, núm. 101, pp. 305-321.

CAMPO, S. del (1973): Cambios sociales y formas de vida, Madrid: Ed. Ariel.

CASTILlo, P. del (1990): "Aproximación al estudio de la identificación partidista en España", Revista de Estudios Políticos, núm. 70, pp. 125-141.

- (ed.) (1995): Comportamiento politico y electoral, Madrid: CIS.

Castillo, P. del, y Crespo, I. (eds.) (1997): Cultura Politica, Valencia: Ed. Tirant lo Blanch.

- (1997): «Elementos de Cultura Política en la Unión Europea», en P. del Castillo e I. Crespo (eds.), Cultura Politica, Valencia: Ed. Tirant lo Blanch, pp. 63-88.

Cazorla, J. (1988): «Cambio social y cultura política», Documentación Social, núm. 73, pp. 7385.

- (1990): "La cultura política en España», en S. Giner (ed.), España. Sociedad y Política, Madrid: Espasa-Calpe.

Cotarelo, R., et al. (1992): Transición politica y consolidación democrática española (19751986), Madrid: CIS.

Cruz, R., y Pérez Ledesma, M. (eds.) (1997): Cultura y movilización en la España contemporánea, Madrid: Alianza Ed.

Díaz-SAlazAR, R. (1990): «Política y religión en la España contemporánea», REIS, núm. 52, pp. 65-83.

DíAZ-SALAZAR, R., et al. (1990): La transición española: religión y politica, Madrid: Ed. Verbo Divino.

Díaz-Salazar, R., y Giner, S. (eds.) (1993): Religión y sociedad en España, Madrid: CIS. 
EdLes, L. D. (1998): Symbol and Ritual in the New Spain, Cambridge: Cambridge University Press.

Elejabeitia, C. de (1988): «Educación y cultura política», Documentación Social, núm. 73, pp. $59-72$.

ENGELL, K. (1986): «El concepto de cultura política: ¿un trabajo de Sísifo o acumulación científica? Reflexiones adicionales al estudio de la cultura política española estudiada en base a textos escolares", Revista Internacional de Sociología, núm. 2, pp. 205-241.

Fraga, M., et al. (1973): La España de los años setenta, Madrid: Moneda y Crédito.

FUNES, M. J. (1998): La salida del silencio, Madrid: Ed. Akal.

GAITÁN, J. A. (1992): «La opinión del diario El País en la transición española», REIS, núm. 57, pp. 149-164.

García, S. (1994): «Ciudadanía en España», en A. Alabart, S. García y S. Giner, Clase, poder y ciudania, Madrid: Ed. Siglo XXI, pp. 225-244.

GARCÍA DE LEÓN, M. A. (1982): Las élites femeninas españolas, Madrid: Ed. Queimada.

- (1994): Élites discriminadas. Sobre el poder de las mujeres, Madrid: Anthropos.

Gibbins, J., et al. (1989): Contemporary Political Culture, London: Sage.

GINER, S. (1993): «Religión civil», REIS, núm. 61, pp. 23-55.

Giner, S., et al. (1990): España: Sociedad y Política, Madrid: Ed. Espasa-Calpe.

GonzÁlez, C. (1997): «Actitudes políticas en Europa del Este», en P. del Castillo e I. Crespo (eds.), Cultura Política, Valencia: Ed. Tirant lo Blanch, pp. 89-114.

Graham, H. (ed.) (1995): Spanish Cultural Studies: an Introduction. The Struggle for Modernity, Oxford: Oxford University Press.

Gunter, R. (1992a): "Politics and Culture in Spain», en A. Wildavsky et al., Politics and Culture, Berkeley: University of California Press.

- (1992b): Politica y cultura en España, Madrid: CEC.

GurrutXaGA, A. (1985): El código nacionalista vasco durante el franquismo, Barcelona: Anthropos.

- (1996): La transformación del nacionalismo vasco, Donostia: R\&B.

Justel, M. (1992): «Edad y cultura política», REIS, núm. 58, pp. 57-96.

- (1993): La abstención electoral en España, 1977-1993, Madrid: CIS.

LAZAR, M. (1990): «Damné de la terre et homme de marbre. L'ouvrier dans l'imaginaire du PCF du milieu des années trente à la fin des années cinquante», Annales ESC, vol. 45, núm. 5, pp. 1071-1096.

LINZ, J. J. (1987): La quiebra de las democracias, Madrid: Alianza Ed.

LIPSET, S. M. (1959): «Some social requisites of democracy: economic development and political Legitimacy», American Political Science Review, pp. 69-106.

LLERA, F. (1989): «Continuidad y cambio en la política vasca: Notas sobre identidades sociales y cultura política», REIS, núm. 47, pp. 107-135.

- (1994): Los vascos y la política. El proceso politico vasco: elecciones, partidos, opinión pública y legitimación en el País Vasco, 1977-1992, Bilbao: Universidad del País Vasco.

- (1997): «Enfoques en el estudio de la cultura política», en P. del Castillo e I. Crespo (eds.), Cultura Politica, Valencia: Ed. Tirant lo Blanch, pp. 39-62.

López Pina, A., y Aranguren, E. (1976): La cultura política en la España de Franco, Madrid: Taurus.

LÓPEZ PINTOR, R. (1982): La opinión pública española del franquismo a la democracia, Madrid: CIS.

LÓPEZ PINTOR, R., y BUCETA, R. (1975): Los españoles de los años setenta: una versión sociológica, Madrid: Tecnos.

LÓpez Pintor, R., y Wert, J. I. (1982): «La otra España. Insolidaridad e intolerancia en la tradición político-cultural española», REIS, núm. 19, pp. 7-25.

Maravall, J. M. (1978): Dictadura y disentimiento político, Madrid: Ed. Alfaguara.

- (1982): La politica de la transición, Madrid: Ed. Taurus.

Maravall, J. M., y Santamaría, J. (1989): "Crisis del franquismo, transición política y consolidación de la democracia en España», en J. F. TezANOS et al., La transición política española, Madrid: Ed. Sistema. 
MartíneZ, A. (1997): «Élites parlamentarias y cultura política en América Latina», en P. del Castillo e I. Crespo (eds.), Cultura Politica, Valencia: Ed. Tirant lo Blanch, pp. 115-154.

McDonough, P.; López Pina, A., y Barnes, S. H. (1988): "The Growth of Democratic Legitimacy in Spain", Comparative Political Studies, vol. 21, pp. 200-230.

- (1998): The Cultural Dynamics of Democratization in Spain, Ithaca: Cornell University Press.

Molinari, J. P. (1991): Sociologie de l'adhésion ouvrière au PCF, Thonon-les-Bains: l'Albaron.

Montero, J. R. (1990): Non Voting in Spain: Some Quantitative and Attitudinal Aspects, Barcelona: Institut CPS, Working Paper.

- (1992): Sobre la democracia en España: legitimidad, apoyos institucionales y significados, Madrid: Centro de Estudios Avanzados en Ciencias Sociales, Fundación Juan March.

- (1993): «Los significados de la democracia en España. Un análisis exploratorio», Inguruak, núm. 7, pp. 61-82.

Montero, J. R., y Morlino, L. (1993): "Legitimidad y democracia en el sur de Europa», REIS, núm. 64, pp. 7-40.

Montero, J. R., y Torcal, M. (1990): «La cultura política de los españoles: pautas de continuidad y cambio», Sistema, núm. 99, pp. 39-74.

MonZón, C. (1988): «La transformación de la cultura política de los españoles», Documentación Social, núm. 73, pp. 103-122.

Morán, M. L. (1988): "Cultura política y democracia en España», Documentación Social, núm. 73.

- (1992): «Algunas reflexiones en torno a la influencia de los medios de comunicación en la formación y características de la cultura política de los españoles», REIS, núm. 57, pp. 37-61.

- (1996): «Sociedad, cultura y política: continuidad y novedad en el análisis cultural», Zona Abierta, núms. 77-78, pp. 1-30.

- (1997a): ¿Y si no voto qué? La participación política en los años ochenta», en R. Cruz y M. Pérez Ledesma (eds.), Cultura y acción colectiva en la España contemporánea, Madrid: Alianza Ed.

- (1997b): «Élites y cultura política en la España democrática», en P. del Castillo e I. Crespo (eds.), Cultura Política, Valencia: Ed. Tirant lo Blanch, pp. 185-222.

- (1998): «La cultura política de los españoles», en S. del Campo (coord.), España, sociedad industrial avanzada, vista por los nuevos sociólogos, Madrid: Real Academia de Ciencias Morales y Políticas, pp. 134-157.

- (en prensa): «Une histoire d'incommunicabilité: récits et culture politique en Espagne et au Pays Basque», en M. Lazar y D. Cefaï (eds.), Cultures Politiques, París: PUF.

MorÁn, M. L., y BENEDicto, J. (1995): La cultura política de los españoles. Un ensayo de reinterpretación, Madrid: CIS.

Oberschall, A. (1996): "Opportunities and framing in the Eastern European revolts of 1989», en McAdam et al., Comparative Perspectives on Social Movements, Cambridge: Cambridge University Press, pp. 93-121.

O’Donnell, G.; Schmitter, P., y Whitehead, L. (1986): Transitions from authoritarian rule. Southern Europe, London: Johns Hopkins University Press.

Orizo, F. (1992): Los nuevos valores de los españoles. España en la Encuesta Europea de Valores, Madrid: Fundación Santamaría.

- (1995): Dinámica intergeneracional en los sistemas de valores de los españoles, Madrid: Opiniones y Actitudes, CIS.

Ortega, F. (1994): "Del patrimonialismo a la competitividad: élites y sistema de valores en España», Revista Mexicana de Sociología, año LVI, núm. 3, pp. 1-23.

Paramio, L. (1985): «La Cultura Política durante la transición», Leviatán, núm. 22, pp. 95-104.

Paramio, L., y Pérez Reverte, J. M. (1980): "Contra las cuerdas», en F. Claudín (ed.), ¿Crisis de los Partidos Politicos?, Madrid: Dédalo.

Pateman, C. (1980): "The Civic Culture: A Philosophic Critique», en G. Almond, S. Verba et al., The Civic Culture Revisited, Boston: Little Brown.

Percheron, A. (1993): La socialisation politique, París: Armand Colin.

Pérez Agote, A. (1987): El nacionalismo vasco a la salida del franquismo, Madrid: CIS.

- (1988): La construcción del nacionalismo vasco, Madrid: CIS. 
PÉrez DíAZ, V. (1979): Clase obrera, partidos y sindicatos, Madrid: Fundación INI.

- (1991a): La emergencia de la España democrática: la invención de una tradición y la dudosa institucionalización de una democracia, Madrid: Working Papers, Fundación Juan March.

- (1991b): "La emergencia de la España democrática», Claves de la Razón Práctica, núm. 13, pp. 62-80.

- (1993): La primacía de la sociedad civil, Madrid: Alianza Ed.

Putnam, R. (1993): Making Democracy Work, Princeton: Princeton University Press.

Rodríguez IbÁNEZ, J. E. (1987): Después de una dictadura: cultura autoritaria y transición política en España, Madrid: CEC.

Rodríguez Osuna, J. (1978): Población y desarrollo en España, Madrid: Cupsa Ed.

RoIz, M. (1988): «Medios de comunicación de masas y cultura política», Documentación Social, núm. 73, pp. 87-101.

SÁNCHEZ, M. (1988): "Cultura organizativa y cultura política», Documentación Social, vol. 73, pp. 159-171.

Revista Española de Investigaciones Sociológicas (1992): Número monográfico sobre «El cambio social y la transformación de la comunicación», coordinado por M. Martín Serrano, núm. 57, Madrid: CIS.

TejerInA, B. (1992): Nacionalismo y lengua, Madrid: Ed. Siglo XXI.

Tejerina, B., et al. (1995): Sociedad civil, protesta y movimientos sociales en el País Vasco, Vitoria: Servicio Central de Publicaciones del Gobierno Vasco.

Tezanos, J. F.; Cotarelo, R.; De Blas, A., et al. (1989): La transición democrática española, Madrid: Ed. Sistema.

TORCAL, M. (1989): «La dimensión materialista-postmaterialista en España: Las variables del cambio cultural», REIS, núm. 47, pp. 227-254.

- (1992): "Análisis dimensional y estudio de valores: el cambio cultural en España», REIS, núm. 58, pp. 97-122.

Unzueta, P. (1988): Los nietos de la ira: nacionalismo y violencia en el País Vasco, Madrid: El País.

VArela, H. (1990): La legalización del PCE: élites, opinión pública y simbolismos en la transición, Working Papers, Fundación Juan March.

VERRET, M. (1988): La culture ouvrière, St. Sébastien: ACL Capus.

VIros, R. (1994): A Qualitative Approach to Electoral Abstention, Barcelona: CPS, Working Paper.

Wallerstein, I. (1995): Unthinking Social Science, Cambridge: Polity Press.

Welch, S. (1993): The Concept of Political Culture, Basingstoke: Macmillan.

ZdRAVOMYSLOVA, E. (1996): "Opportunities and framing in the transitions to democracy: the case of Russia", en McADAm et al., Comparative Perspectives on Social Movements, Cambridge: Cambridge University Press, pp. 122-137.

Zona Abierta (1996): Número monográfico sobre "Cultura y Política», coordinado por M. L. Morán, núms. 77-78, Madrid: Fundación Pablo Iglesias. 


\begin{abstract}
Studies on political culture have played a very important role in Spanish socio-political research. The ten-year period from the mid-1960s to the death of Franco marks the reception of the classic paradigm of political culture and the first steps towards its application in studies on the modernisation process, in the analyses of the evolution of the Franco regime and in the first indications of the inevitable political change. The most widespread interpretations of the nature of the political transition emphasised the existence of a set of cultural prerequisites which facilitated democratisation. This enabled the elites to establish a basic pact on which a democracy comparable with that of the countries of Western Europe was built, in a very short period of time. Throughout the $1980 \mathrm{~s}$ and the $1990 \mathrm{~s}$, there has been a sustained interest in studying the political culture of Spaniards. Notwithstanding, now that democratic life has become routine, a certain shift of emphasis has been denoted in the topics researched.
\end{abstract}

